\title{
Insights and Inspiration from Explorative Research into the Impacts of a Community Arts Project
}

\author{
Gwenda Van der Vaart
}

\section{Introduction}

For researchers focusing on the question of how communities can be strengthened for a more sustainable future, working at the crossroads of science, arts and society can provide interesting opportunities. Not surprisingly, an increase of academic work related to this intersection can be witnessed (e.g., Brice \& Fernández Arconada, 2018; Coemans \& Hannes, 2017; Hawkins, 2011). There are several types of relationships between the fields of arts and science. Wang et al., (2017, p. 6), for instance, distinguish between "research about art, art as research, and art in research". As this book demonstrates, researchers interested in resourceful and resilient community practices use a variety of creative and/or arts-based methods in their work. In this context though, looking

\footnotetext{
G. Van der Vaart (凶)

Department of Spatial Planning and Environment, University of Groningen, Groningen, The Netherlands e-mail: g.van.der.vaart@rug.nl
} 
at artistic practices themselves can also provide valuable insights for such researchers in order to learn more about ways in which communities can be strengthened.

Over the past decades, an expansion from the arts beyond galleries into society took place, with artists actively engaging with particular social contexts (Brice \& Fernández Arconada, 2018). Various terms are adopted in this context, such as community-based art, socially engaged art, sitespecific art, social practice, dialogic art, interventionist art, contextual art, and collaborative art (Bishop, 2012; Simoniti, 2018). The objectives and output of artists involved in this kind of art vary enormously, but, as Bishop (2006, p. 179) notes, they all share "a belief in the empowering creativity of collective action and shared ideas". In line with this, there are many examples of artists who actively work with communities and aim, through their work, to contribute to that community (Guetzkow, 2002; Matarasso, 2007).

Recently, there has also been increasing attention for and recognition of the role artists can play in contributing to a community's resilience specifically. Neal (2015), for instance, argues that artists play a crucial role in rethinking the future and can help to reinvent and reimagine our world. She regards artists as 'agents of change', whom:

can be circuit breakers of tragedy, surprising people with alternative ways of seeing, jolting them awake from denial and speeding up a public process of seeing and feeling the "truth" of climate change [...] opening possibilities for change and renewal. (p. 7)

For communities that want to develop themselves towards a more sustainable future, especially community arts projects (in which an artist actively works together with the community members) appear to hold much potential (see Anwar McHenry, 2011; Burnell, 2012; Derrett, 2008; Mulligan et al., 2006; Stocker \& Kennedy, 2011; Van der Vaart, 2018). Ferreira and Duxbury (2017, p. 46) note that participation in the arts "can be a powerful driver for individual and collective capacity to (individually and collectively) rethink values, norms, and behavioural conducts". Horlings (2017, p. 137) explains that these relate to the 
"inner' dimension of sustainability" that, next to practical behaviour and politics, accelerates change towards sustainability.

In addition, community arts projects can contribute to a community's resilience because of their ability to enhance links between community members, their community and the wider surroundings. Subsequently, this can stimulate people's willingness as well as ability to work together for a common good, and empower them to engage in other types of civic activities to protect and pursue their collective interests (Anwar McHenry, 2011; Derrett, 2008; Larsen et al., 2004). In this context, McCarthy et al. (2004) speak of the role the arts can play in building a community's 'organizational capacity'. According to their literature review on the benefits of the arts at the community level, this is stimulated in three ways, by: developing local arts groups and leaders, promoting cooperation among arts and non-arts groups, and "the more general process of people organizing and getting involved in civic institutions and volunteer associations" (p. 14).

This chapter takes as its empirical focus one such community arts project: the theatre-trilogy Grutte Pier. This project took place in the Frisian village Kimswerd, the Netherlands, between 2014 and 2018. The chapter reflects on an explorative research project into the impact of this community arts project on the village of Kimswerd. By discussing what researching such artistic practices can bring, the chapter draws wider lessons for researchers interested in community engagement, place-based action, and community resilience.

The chapter is structured as follows: first, more background on the relationship between the arts and community resilience is provided and concerns related to evaluating the impacts of community arts projects are discussed. Then the Grutte Pier community arts project and the research project are further introduced. The next sections first provide a reflection on researching such an artistic practice, and then summarize and reflect on the reported impacts of the Grutte Pier project on the community of Kimswerd. The chapter finishes with a discussion and conclusions on what researching community arts projects can bring to researchers interested in achieving meaningful change in communities in order to prepare them for a more sustainable future. 


\section{Community Resilience and the Arts}

When you are interested in the sustainable development of communities, it is nearly impossible to avoid encountering the concept of resilience. Over the past decades, despite attracting sustained critique by some (see, e.g., Kaika, 2017; Porter \& Davoudi, 2012), this term has become widely used in both academia and practice in order to discuss how communities can cope with the changes and uncertainties they face (Pendall et al., 2010; Revell \& Dinnie, 2020; White \& O'Hare, 2014). The concept of resilience is put in the spotlight even more because of the increasingly louder calls for transformative, sustainable change in light of current pressing global issues such as climate change, but also the COVID-19 pandemic, that underscores the current unsustainable system.

There is a wide variety of interpretations of resilience to be found in the literature (see, e.g., Davoudi, 2012; Hutter \& Kuhlicke, 2013; Pendall et al., 2010). At its base though, when linked to communities, an evolutionary understanding of resilience revolves around the question of how communities can shape and respond to the challenges they face in order to achieve a better future (see Davoudi, 2012). Resilient communities are considered as being able to utilize and develop their resources to respond and adapt to challenges as well as opportunities that are brought about by changes (Revell \& Dinnie, 2020).

Several scholars stress that the everyday lifeworld and local knowledge of communities should be incorporated when planning for community resilience (see, e.g., Steiner \& Markantoni, 2013). Traditionally, however, "the majority of work in the burgeoning field of resilience [...] has not been grounded within the everyday practices of communities of policy and practice" (Coaffee, 2013, p. 327). Top-down, managerialist approaches to resilience raise certain questions, as Brice and Fernández Arconada (2018, p. 225) rightfully point out: how are resilience objectives identified and achieved? And "by what methods [can] these initiatives [...] be kept relevant to specific places and specific communities"?

In light of the above, turning to community arts holds much potential. In using the term community arts, it is referred to as "a collective method of art-making, engaging professional artists and self-defined communities 
through collaborative artistic expression" (Ontario Arts Council, 1998, p. 7). This art form fundamentally depends on actively engaging people in the creative process and, therefore, unlocks their everyday, lived experiences. This aligns with resilience policies that are directed towards smaller spatial scales and everyday activities (Coaffee, 2013), and can help to take the specific socio-spatial context of a community into account (see also Christopherson et al., 2010; Hutter \& Kuhlicke, 2013; O’Hare \& White, 2013).

\section{Evaluating Impact}

As noted, community arts projects can provide valuable insights and inspiration to researchers interested in community engagement, placebased action, and community resilience. However, when researching such artistic practices to assess their impact, certain issues are at stake.

First, when looking at the value of such projects for community resilience, it is important to realize that they are not a panacea. Positive outcomes of community arts projects cannot be taken for granted and projects can also have negative outcomes. As Matarasso (1997, p. 75) already noted in his classic work Use or Ornament?: "the arts are not fast-food, predictable in content in every place and on every occasion". Therefore, a nuanced perspective on the effects of the arts is required (see also McCarthy \& Jinnett, 2001; Mulligan et al., 2006). Moreover, in the literature, potential barriers to engaging in the arts are noted and, related to this, concerns around the extent to which a community is involved are expressed (see, e.g., Anwar McHenry, 2011; Balfour et al., 2018; Mulligan et al., 2006; McCarthy \& Jinnett, 2001). A key lesson here is that context matters. The influence of the arts is context-dependent, with the arts, for instance, having both binding and dividing effects for different (groups of) community members at the same time (Van der Vaart et al., 2017). On their own, the arts cannot provide the solution to communities and therefore, should be considered as one of several potential means in community development processes (Burnell, 2012; Matarasso, 2007; Van der Vaart et al., 2017). 
Another important issue at stake when discussing the value of community arts, especially in light of certain (community) development goals, is that there are concerns and tensions around evaluating the arts. Over the years, evidencing the impacts of arts projects has become more important. Belfiore and Bennett (2010) point out that there is a commitment of Western governments towards evidence-based policy-making: "to measure and assess the extent to which the subsidized arts have a socio-economic impact" (p. 122), and therefore whether they contribute to policy (or not). As a result, initiators of arts projects are increasingly pressurized to articulate the public value of their work in light of funding criteria and the need to effectively appeal to the general public and its legislative representatives (McCarthy et al., 2004). Belfiore and Bennet (2010) observe that this encouraged a blooming of impact studies and the development of a "toolkit mentality" (p. 122), with a search for a straightforward method of impact evaluation that can be applied in different contexts.

Many art advocates, however, have a resistance to, or negative perceptions of, evaluation (Reeves, 2002). According to Jermyn (2001), this resistance can be composed of several elements including lack of time, resources or skills, but also lack of motivation, inclination or understanding about the value of evaluation (outside the context of funding relationships). She points out that art practitioners rarely regard evaluation and monitoring as central or integral to their work. In addition, Jermyn (2001) notes there are fears connected to the appropriateness of available evaluation methods, such as that it "will fail to reflect the spirit of the arts activity, stifle creativity or somehow reduce the arts experience" or that "the utility of the arts will be overstated at the expense of less measurable benefits" (p. 9).

This latter fear connects to concerns around the 'instrumentalization' of the arts, expressed by artists as well as scholars (see, e.g., Brice \& Fernández Arconada, 2018; McCarthy et al., 2004; Mulligan et al., 2006; Khan, 2010; see also Leitheiser et al., this book). These concerns boil down to an (perceived) imbalance, whereby the instrumental benefits of the arts overshadow or suppress their intrinsic benefits. Here, arts advocates express concerns with regard to only funding the arts based on their instrumental benefits. The instrumentalization of the arts also leads to 
debate on how exactly to understand and judge 'quality' in the arts (see, e.g., Bishop, 2006; Simoniti, 2018). There is a tension between utility on the one hand and aesthetics on the other (Brice \& Fernández Arconada, 2018).

Finally, there are scholars who take a critical stance towards arts impact research and who point to tensions between "genuine research and research for the sake of advocacy" (Belfiore, 2009, p. 353; see also Belfiore \& Bennett, 2010). Belfiore (2009) notes that there is an evident temptation in this field to articulate research questions in advocacy- or policy-friendly terms, noting that as a consequence:

research has often focused on asking how the presumed positive social impacts of the arts might be measured or enhanced, rather than in asking whether the arts have social impacts of the sort claimed for them, if these impacts can be expected to be positive and, more generally, whether it is possible to generalise people's experiences of the arts within arts forms, across art forms and across the very diverse population represented by those who engage with the arts. (p. 353, original emphasis)

Consequently, some scholars argue for a separation of arts advocacy from rigorous impact evaluation research (Belfiore \& Bennett, 2010), and point to the need for carefully thought-through research questions (Belfiore, 2009), with researchers proceeding "along clear lines" while making "explicit the theories underpinning [their] research" (Merli, 2002, p. 115).

\section{PeerGrouP, Grutte Pier and the Research Project}

A story becomes stronger when it is told. Like a tree can grow when it receives sunlight and water. You came here for a story about Grutte Pier. His story got strong roots. And a tree with strong roots blossoms every year. (translated quote from "De Bezinning", 2017-2018) 
These are the opening lines of the final round of performances connected to the Grutte Pier theatre trilogy. This community arts project took place in the Dutch village Kimswerd between 2014 and 2018. The project was initiated by PeerGrouP, a site-specific theatre company in the northern Netherlands. PeerGrouP describes its work as "site-specific in a socially engaged manner" (PeerGrouP, 2020). On its website, PeerGrouP's special approach to its productions is explained; this starts with PeerGrouP's employees coming to a community as outsiders:

Integrate and infiltrate. In this approach they [the employees] are working on a site and trying to find a (temporary) place in the community. By making use of the local artistic skills and fascinations, curiosity awakens. This is a starting point: from curiosity grows complicity and from complicity a desire to cooperate might emerge. (Ibid.)

Actively collaborating with local people plays an important role in PeerGrouP's productions. According to their vision, they aim to make theatre in and with a community, telling stories about the place in which they are performing. Hereby they strive to achieve a lasting effect on the community (PeerGrouP, 2019). As expressed in PeerGrouP's policy plan, PeerGrouP regards it as their civil mission to "challenge the community, entrepreneurs, politics and science to actively contribute to a transition to a sustainable society" (PeerGrouP, 2016, translated). In light of this, PeerGrouP works on projects in which they make connections with scientists, experts, organizations, and people from the community itself. Moreover, they strive to make such connections in such a manner that a follow-up is also possible (Ibid.).

The Grutte Pier trilogy in Kimswerd was one of the major productions of PeerGrouP at that time. The project revolved around the life of the village's historical figure Grutte Pier. This is a nickname of Pier Gerlofs Donia (meaning 'Big Pier') and refers to his allegedly legendary size and strength. Grutte Pier lived in Kimswerd between 1480 and 1520 and led the rebellion against the oppressors of Friesland. In keeping with the above introduction to PeerGrouP, the theatre company's approach to the project involved active collaboration with the inhabitants of Kimswerd (a village of nearly 500 inhabitants), as well as other volunteers from the 
wider region. During the years that the project ran in the village, PeerGrouP and the community worked together towards a trilogy around three main performances ${ }^{1}$ :

1. De Brân, which involved a reconstruction of Grutte Pier's farm and a one-off event on 29 January 2015 (1,534 visitors). During the performance, the reconstructed farm was symbolically set on fire. Through this act, it was commemorated that it was 500 years ago that Grutte Pier's farm was burned down, which ignited his anger and made him start the rebellion against the occupiers of Friesland.

2. Grutte Pier fan Kimswert, a large open air spectacle around the life and mission of Grutte Pier; this was performed 27 times during the summer of 2016 (9,094 visitors).

3. De Bezinning, a more intimate performance based on the last years of Grutte Pier's life (which he spent in a monastery); this was staged in the church of Kimswerd (and two other locations outside the village) and was performed 12 times in the winter of 2017-2018 (653 visitors).

During the last part of the trilogy, I was asked by PeerGrouP to conduct a small research project into the Grutte Pier project. They were curious about the impact of their long-term involvement in Kimswerd on the village, as seen from the perspective of the inhabitants. The research project was therefore commissioned on behalf of PeerGrouP, but as a researcher I had freedom in designing and undertaking the project. The objective of the research project was to explore whether the Grutte Pier project had an impact on the village and if so, to provide insight into the nature of this impact. The project involved in-depth interviews and questionnaires and was conducted between December 2017 and February 2018.

Participants for the interviews were recruited through snowball sampling and random door-to-door recruiting. In total, 12 interviews were conducted with 13 different persons (including one married couple

\footnotetext{
${ }^{1}$ In addition to these main performances there were several side-events/spinoffs organized in relation to the Grutte Pier trilogy, to generate further attention for the project.
} 
that was interviewed at the same time) comprising: (a) 3 volunteers who were part of the so-called 'village team'-a group of inhabitants actively involved in the overall organization of the Grutte Pier project; (b) 3 volunteers that participated in a (small) part the project; (c) 4 inhabitants who did not participate in the project but who visited the performances (including the married couple); and (d) 3 inhabitants who neither participated in the project nor visited the performances. The interviews focused on topics such as people's connection to Kimswerd, their involvement in the Grutte Pier project, and their opinion on, and experiences with, PeerGrouP and the project.

The questionnaires were handed out after three performances of the last part of the trilogy in Kimswerd. The questionnaire consisted of mostly brief open-ended questions and covered topics such as visitors' initial response to the performance, their reasons for visiting, their connection to Kimswerd and knowledge of Grutte Pier's story, their involvement in the project themselves, and whether they experienced any effects of the project (and which). In total, 50 questionnaires were completed by the visitors.

The interviews were recorded and transcribed, and both the interviews and questionnaires were coded inductively to analyze the various effects that emerged from the data. As the interviews were conducted in Dutch, the quotes in the following sections are all translated by the researcher (Van der Vaart). Hereby, fictional names are used.

In the following sections I will first provide reflections on researching such an artistic practice and then summarize and reflect on the effects of the Grutte Pier project that emerged from the interviews and questionnaires.

\section{Researching a Community Arts Project}

Evidencing the impact of community arts projects has become more important over the years, as noted above. However, there is no consensus on what the best evaluation methods for assessing the impact of such projects are (Belfiore, 2006; Reeves, 2002). While some scholars underline the need for more definitive quantitative evidence in order to 
demonstrate the impact of the arts, others argue that the development of evaluation techniques beyond the quantitative is needed (see, e.g., Belfiore, 2006; Mulligan et al., 2006). In addition, Merli (2002) points to the context-dependent nature of the impact of the arts, stating that differences are likely to exist and that there is a need to know more about this. She argues that: "without knowing what the real, specific effects of the arts are, and in which circumstances they occur [...] researchers are only going to measure what they would like to be there" (p. 115). In light of this, it is important to not only 'measure' impacts, but to 'understand' people's experiences, ideas and feelings (Merli, 2002). Such an approach aligns with the 'critical research ethos' that Belfiore (2009) advocates. She points to the need for explorative research that is:

indifferent to the requirements of advocacy [and] aims to describe, explore and illuminate complex issues around the role and condition of culture, cultural production, consumption and administration in contemporary society. (p. 354)

Although being small-scale, it is worthwhile to briefly reflect on some choices that were made in undertaking the explorative research project in Kimswerd, in order to draw lessons for future work.

First, the research project consisted of both questionnaires and interviews. Choosing this mix of methods proved to be helpful in obtaining both a more general impression of the Great Pier project from the visitors' side and a more in-depth understanding of inhabitants' opinions and experiences with the arts project in their village. As the research project aimed to explore the arts project's effects as experienced by the inhabitants of Kimswerd, I decided to only interview inhabitants themselves and not people working at PeerGrouP. Here, I also deliberately opted for interviewing both inhabitants who were involved in the project (to various degrees) and those who were not. It was interesting to have this mix of interviewees, to explore if and how this impacted the way people perceived and experienced the project.

The research project was conducted near the end of the Grutte Pier trilogy, as it was only in the autumn of 2017 that PeerGrouP approached me to conduct an explorative research project into the effects of their 
arts project. This rather late timing seems to support Jermyn's (2001) earlier noted observation that art practitioners rarely regard evaluation and monitoring as being integral to their work. In hindsight, while it was still possible to collect data for a small explorative review into the effects of the arts project, a more thorough, overall evaluation of the project would have requested an earlier involvement, ideally directly from the start in 2014. From an evaluation perspective, it would have been interesting to monitor the development of the theatre trilogy and be able to investigate how the inhabitants experienced the project throughout the years. Still, the explorative research project as it was conducted presents valuable insights and inspiration for researchers interested in community engagement, place-based action and community resilience, the next section, therefore, turns to the findings of the project.

\section{A Project as Strong as Grutte Pier Himself?}

Overall, a highly positive image of the Grutte Pier trilogy arose during the research project. Many interviewees regarded the Grutte Pier project as a unique project that was very successful and argued that only this project could have achieved the effects that it did to this extent. When asked to elaborate on what they saw as specific strengths of the project, the interviewees mentioned four strengths: the size of the project; the popularity and authenticity of the story of Grutte Pier; the fact that the project connected people with one another; and that it involved the community to a great extent. These factors helped PeerGrouP to engage a large portion of the inhabitants in the project. Ann (village-team), for instance, remarked:

If you wanted to do something, you could participate, in any way whatsoever. Whether you were sitting behind the cashier, were sewing [a costume], or controlling traffic, you are doing it all together [...] I think that's the strength of PeerGrouP [...] It is being propagated very enthusiastically, so you actually feel like participating yourself too. 
In addition, the interviews also revealed that the unfamiliarity of PeerGrouP's employees - their 'other set of eyes'-seemed to be related to the project's success. Interviewees noted that this also contributed to the great enthusiasm of a large number of inhabitants to volunteer for the project. Ursula (village-team) explained this as follows:

I think the unfamiliar faces actually made everyone feel involved. For instance, Peter $[\ldots]$ the chairman of Dorpsbelangen [village interest group], he is a good speaker and technically he could be able to do it in the same way, but then the people would have thought 'yeah right Peter'. But I think that would be because he is a face of the village [...] now, they were new faces in the village and that gave a very good and positive feeling.

As described above, PeerGrouP works via an integrate and infiltrate' approach, hoping that a desire to cooperate might emerge from people's initial curiosity. Apparently, this approach paid off enormously in Kimswerd. Following on from PeerGrouP's vision, they subsequently strived to achieve a lasting effect on the community in - and withwhich they work.

The interviewees that participated in the Grutte Pier project themselves raised several kinds of personal effects. These are related especially to people's personal growth, social life, and feelings of pride. Some indicated that they experienced personal growth and developed certain skills due to their involvement in the project. This finding corresponds to earlier work from, among others, Matarasso (2007) and Newman et al. (2003). Becoming more assertive, developing a broader social outlook, and improving planning and communication skills are examples of the personal impacts that were mentioned. Amber (who participated in the farmers' choir ${ }^{2}$ ), for instance, opened up about the following personal change she experienced:

A change in my being [...] I am more combative. I stand up for myself more $[. .$.$] and I am more daring. I am also part of a [different ]$ choir, and

\footnotetext{
${ }^{2}$ The famers' choir was specifically formed as part of the project and played a role in the performances.
} 
I just dare to be myself there. Before I never dared, I was always sitting in the back corner, everywhere. So nobody would see me. Well, that is changed.

In addition to such personal effects, the interviews and questionnaires also revealed several effects at the village level. The following quote symbolizes a broader pattern that can be observed in this regard. Alice (who did not participate or visit) answered the question whether the project resulted in certain effects on the village as follows:

I cannot really assess that properly. In terms of sense of community you mean, right? Yeah I did not feel that, because I was not part of it [...] I believe that, if you get involved in that, let's say the 'mienskip' [note: Frisian word for community], that it certainly has a strengthening effect.

In line with Alice's statement, not everybody among the interviewees perceived the effects of the Grutte Pier trilogy on the community of Kimswerd to the same extent. Understandably perhaps, those who were themselves actively involved in the project noted the effects, while those who were less or not at all involved mentioned the effects less often or to a lesser extent (see also Van der Vaart et al. (2017) for a similar finding in a different context). In contrast to this finding though, in the case of the questionnaire responses, visitors who themselves were not actively involved in the project noted several positive effects of the project on Kimswerd.

The questionnaire included four open-ended questions on the effects of the Grutte Pier project. Visitors were asked if and what the project brought them personally, what they thought it brought to the village, and whether the project had any negative effects in their eyes (also specified on a personal and village level). The most often indicated village level effects were that the project put Kimswerd on the map and generated attention regarding its history. These findings were supported by the interviews. The interviews, in turn, revealed that these effects also fed into a sense of pride among the inhabitants and could result in a boost of one's identity. The interviewees expressed a certain degree of pride, both with regard to the Grutte Pier project and their village. They noted 
that they were proud that the project took place in their village and that the inhabitants-together-made it into such a success.

The village level effects that were most often mentioned during the interviews were that the project created and strengthened bonds between Kimswerd's inhabitants. Participants expressed that, thanks to the project, they got to know more people and/or got to know people better. Here, many interviewees also remarked that the project strengthened the general sense of community in Kimswerd. Phil (village-team), for instance, noted:

the people who have been working with each other in the village in the past years [during the project], they also meet each other more often and work together more often. So it has done a lot for the social bonding in the village. Every night you had a large amount of volunteers on the move [...this] certainly contributed to a closer bond between a lot of people in Kimswerd.

As a subsequent result of these effects, some interviewees also saw a smoother way of collaborating as an effect of the Grutte Pier project. They noted that people could find each other quicker when they need help and had a shared 'success experience', which gives confidence. Thanks to the success of the project, people discovered how much is possible to accomplish by working together. In this sense, the project contributed to a certain awareness of, and confidence in, people's own ability. This all feeds into the 'organizational capacity' of the community that McCarthy et al. (2004) speak of, and is highly promising in light of future community development initiatives.

Hardly any negative effects of the Grutte Pier project were mentioned, either in the questionnaires or in the interviews. This absence of negative effects being mentioned corresponds to Newman et al.'s (2003) literature review on community-based arts projects, in which they found that only a few negative consequences of projects were ever mentioned. It could be that the participants might have perceived it as being inappropriate to share any negativities on the Grutte Pier project due to the overall wide support it received in the village-even though they could complete the questionnaire anonymously and the interviews were treated 
confidentially. There was just one interviewee who noted that he had faced some critical comments from colleagues, who were questioning the costs of the project and whether this spending was justified. Some of the interviewees, however, did raise that there might have been certain negative noises about the project, even though they did not encounter these themselves.

For the community in Kimswerd an important question is how long, and to what extent, the above-mentioned effects will continue to have an influence on their village community. At the time the interviews were conducted, the very last performances of the trilogy were taking place or had just finished. At that time, the interviewees found it hard to predict how and to what extent the project might continue to influence the community in the future. Many at least regarded the project as something that will be talked about for a long time and that will be a precious memory for many inhabitants. An entrance ticket for the first part of the trilogy, a wooden slice specially made for the project, got a place in the homes of several inhabitants and forms a tangible artefact in memory of the project.

While one interviewee expressed that she was "afraid it will slowly simmer away in the village" (Ursula-village-team), the other interviewees had higher expectations with regard to the longevity and strength of the project's effects. In addition to the experience of the project being regarded as a dear memory that would long be cherished, people mentioned three effects of the Grutte Pier project that they expected to be longer lasting. First, some people felt that the personal growth they had experienced from taking part would last for the rest of their lives. Second, interviewees expressed their expectation that the boosting of the community's 'organizational capacity' would be long lasting. In their eyes, the project contributed to a smoother way of collaborating in the village and stimulated a certain trust and belief in people's ability to accomplish things together. In light of this, people, for instance, expected that it would be easier to find volunteers for future activities, also when organized by the villagers themselves. Finally, some interviewees indicated that they expected that the Grutte Pier project would serve as an inspirational influence for future activities and would have a follow-up in some way or another. Some interviewees already mentioned certain 
activities that seemed to point in this direction, such as the formation of a new choir in which some of the members of the farmers' choir ${ }^{3}$ participated, and a request for 'jewellery making' workshops to the woman who was responsible for the jewellery of some of the actors.

\section{Lessons Learned}

As this chapter stated at its start, working at the crossroads of science, arts, and society can be insightful for researchers interested in community engagement, place-based action, and community resilience. In this chapter, the Grutte Pier trilogy is extensively discussed, as researching such artistic practices can provide valuable insights and inspiration to researchers. Community arts or participatory arts projects such as this project are often embraced as a form of soft social engineering, with the idea that they can be useful to effect positive changes in society (Bishop, 2012). However, as discussed, evaluating such artistic practices is not a straightforward task. There are several tensions and concerns around evaluating the impact of the arts and there is no consensus on what the best evaluation methods are (Belfiore, 2006; Reeves, 2002). In drawing this chapter to a conclusion, what lessons can be drawn from the explorative research project into the impact of the Grutte Pier project on the village of Kimswerd?

The reflections on the research project support the need to adopt a critical perspective with regard to the value of artistic practices. In order to obtain both a general impression, as well as a more in-depth understanding of people's experiences with the arts, a mix of methods proved to be supportive. Moreover, interviewing people who were involved in the arts project to various degrees, and including those who were not involved, was instrumental in gaining a more nuanced understanding of the project's impact on the village. In the end, the findings from the explorative research project demonstrate that researching such artistic practices can provide insights and inspiration for researchers interested in community resilience.

\footnotetext{
3 See footnote 2 .
} 
To start with, community arts projects seem to be an evocative way of engaging a community and can result in a variety of effects. Altogether, staying close to PeerGrouP's (2019) own terminology, the Grutte Pier project appears to have been a successful community arts project in Kimswerd, being accomplished together with the inhabitants, and with positive effects for the community. The interviewees pointed to several ingredients for its success: the popularity and authenticity of the story of Grutte Pier was regarded as a strength, and both the project's size and long duration were mentioned as reasons why the project achieved its effects to the extent it did. In addition, the fact that the project connected people with one another and involved the community to such a great extent was also mentioned as part of the project's strengths. Interestingly, the unfamiliarity of PeerGrouP's employees also appeared to play a role in the project's success, as this contributed to inhabitants' great enthusiasm to volunteer.

Inferred from the above, and in light of strengthening communities, it appears to be a successful formula to have artists, coming to a community as 'outsiders', actively engaging inhabitants in a large community arts project that is both locally grounded and offers the inhabitants various ways of participating themselves. This finding is different from what Rogers and Spokes (2003) concluded in their study on a community development project in small rural communities in Australia. They regarded the involvement of local artists as an essential element for the engagement of community members and community building objectives, noting that:

local artists were already connected to the community, with a strong desire to improve their own profile and value to the community. (p. 7)

In Kimswerd however, PeerGrouP's 'integrate and infiltrate' approach seemed to play a considerable role in helping to enthuse inhabitants to become involved in the project. As noted, PeerGrouP strives to achieve lasting effects on the communities in and with which they work, and actually regards it as its civil mission to "challenge the community [...] to actively contribute to a transition to a sustainable society" (PeerGrouP, 
2016, translated). This approach aligns with the earlier noted characterization of artists as potential 'agents of change', that can help to change people's mindsets and activate them to become involved (Horlings, 2017; Neal, 2015).

A final important remark needs to be made here, partly linking back to the earlier discussed concerns of the arts not being a panacea for communities. In light of community resilience it is important for community arts projects to achieve sustainable effects in order to have a lasting impact on communities (Askins \& Pain, 2011; Carey \& Sutton, 2004). The opening lines of the last part of the Grutte Pier trilogy spoke of Grutte Pier's story developing strong roots, and reminded the audience that "a tree with strong roots blossoms every year". While at the start of the Grutte Pier project, some people were quite sceptical about its overall feasibility, the project, eventually, showed the inhabitants what they can accomplish when they work together. Such effects can go a long way and can be a great boost for a community's 'organizational capacity' (McCarthy et al., 2004). The interviewees also raised the fact that the trilogy might serve as an inspirational influence for future activities. In this way, the community could reap the benefits of the blossoming 'Grutte Pier tree' for a long time.

\section{References}

Anwar McHenry, J. (2011). Rural empowerment through the arts: The role of the arts in civic and social participation in the mid west region of Western Australia. Journal of Rural Studies, 27, 245-253.

Askins, K., \& Pain, R. (2011). Contact zones: Participation, materiality, and the messiness of interaction. Environment and Planning d: Society and Space, 29, 803-821.

Balfour, B., Fortunato, M.W.-P., \& Alter, T. R. (2018). The creative fire: An interactional framework for rural arts-based development. Journal of Rural Studies, 63, 229-239.

Belfiore, E. (2006). The social impacts of the arts-Myth or reality? In M. Mirza (Ed.), Culture vultures: Is UK arts policy damaging the arts? (pp. 2037). Policy Exchange Limited. 
Belfiore, E. (2009). On bullshit in cultural policy practice and research: Notes from the British case. International Journal of Cultural Policy, 15(3), 343359.

Belfiore, E., \& Bennett, O. (2010). Beyond the 'toolkit approach': Arts impact evaluation research and the realities of cultural policy-making. Journal for Cultural Research, 14(2), 121-142.

Bishop, C. (2006). The social turn: Collaboration and its discontents. Artforum, 44(6), 178-183.

Bishop, C. (2012). Artificial hells: Participatory art and the politics of spectatorship. Verso.

Brice, S., \& Fernández Arconada, S. (2018). Riding the tide: Socially-engaged art and resilience in an uncertain future. In E.-M. Trell, B. Restemeyer, M. M. Bakema, \& B. van Hoven (Eds.), Governing for resilience in vulnerable places (pp. 224-243). Routledge.

Burnell, J. (2012). Small change: Understanding cultural action as a resource for unlocking assets and building resilience in communities. Community Development Journal, 48(1), 134-150.

Carey, P., \& Sutton, S. (2004). Community development through participatory arts: Lessons learned from a community arts and regeneration project in South Liverpool. Community Development Journal, 39(2), 123-134.

Christopherson, S., Michie, J., \& Tyler, P. (2010). Regional resilience: Theoretical and empirical perspectives. Cambridge Journal of Regions, Economy and Society, 3(1), 3-10.

Coaffee, J. (2013). Towards new-generation urban resilience in planning practice: From securitization to integrated place making. Planning Practice \& Research, 28(3), 323-339.

Coemans, S., \& Hannes, K. (2017). Researchers under the spell of the arts: Two decades of using arts-based methods in community-based inquiry with vulnerable populations. Educational Research Review, 22, 34-49.

Davoudi, S. (2012). Resilience: A bridging concept or a dead end? Planning Theory \& Practice, 13(2), 299-307.

Derrett, R. (2008). Regional festival: nourishing community resilience: The nature and role of cultural festivals in Northern Rivers NSW communities. Southern Cross University.

Ferreira, I., \& Duxbury, N. (2017). Cultural projects, public participation, and small city sustainability. In S. Asikainen, C. Brites, K. Plebańczyk, L. Rogač Mijatović, \& K. Soini (Eds.), Culture in sustainability: Towards a transdisciplinary approach (pp. 45-60). University of Jyväskylä, Department of Social Sciences and Philosophy. 
Guetzkow, J. (2002). How the arts impact COMMUNITIES: An introduction to the literature on arts impact studies (Working Paper Series, 20, Princeton University, Center for Arts and Cultural Policy Studies).

Hawkins, H. (2011). Dialogues and doings: Sketching the relationships between geography and art. Geography Compass, 5(7), 464-478.

Horlings, L. (2017). The role of artists and researchers in sustainable placeshaping. In S. Asikainen, C. Brites, K. Plebańczyk, L. Rogač Mijatović, \& K. Soini (Eds.), Culture in sustainability: Towards a transdisciplinary approach (pp. 130-143). University of Jyväskylä, Department of Social Sciences and Philosophy.

Hutter, G., \& Kuhlicke, C. (2013). Resilience, talk and action: Exploring the meanings of resilience in the context of planning and institutions. Planning, Practice \& Research, 28(3), 294-306.

Jermyn, H. (2001). The arts and social exclusion: A review prepared for the arts council of England. Arts Council of England.

Kaika, M. (2017). 'Don't call me resilient again!': The new urban agenda as immunology $\ldots$ or ... what happens when communities refuse to be vaccinated with 'smart cities' and indicators. Environment \& Urbanization, 29(1), 89-102.

Khan, R. (2010). Going 'mainstream': Evaluating the instrumentalisation of multicultural arts. International Journal of Cultural Policy, 16 (2), 184-199.

Larsen, L., Harlan, S. L., Bolin, B., Hackett, E. J., Hope, D., Kirby, A., Nelson, A., Rex, T. R., \& Wolf, S. (2004). Bonding and bridging: Understanding the relationship between social capital and civic action. Journal of Planning Education and Research, 24(64), 64-77.

Matarasso, F. (1997). Use or ornament? The social impact of participation in the arts. Comedia.

Matarasso, F. (2007). Common ground: Cultural action as a route to community development. Community Development Journal, 42(4), 449-458.

McCarthy, K. F., \& Jinnett, K. (2001). A new framework for building participation in the arts. RAND Corporation.

McCarthy, K. F., Ondaatje, E., Zakaras, L., \& Brooks, A. (2004). Gifts of the muse: Reframing the debate about the benefits of the arts. RAND Corporation.

Merli, P. (2002). Evaluating the social impact of participation in arts activities. International Journal of Cultural Policy, 8(1), 107-118.

Mulligan, M., Humphery, K., James, Scanlon, C. P., Smith, P., \& Welch, N. (2006). Creating community: Celebrations, arts and wellbeing within and across local communities. The Globalism Institute.

Neal, L. (2015). Playing for time. Oberon Books. 
Newman, T., Curtis, K., \& Stephens, J. (2003). Do community-based arts projects result in social gains? A review of the literature. Community Development Journal, 38(4), 310-322.

O'Hare, P., \& White, I. (2013). Deconstructing resilience: Lessons from planning practice. Planning Practice \& Research, 28(3), 275-279.

Ontario Arts Council. (1998). Community arts workbook. Ontario Arts Council.

PeerGrouP. (2016). PeerGrouP 2017-2020 radius. PeerGrouP.

PeerGrouP. (2019). Bestuursverslag. PeerGrouP.

PeerGrouP. (2020). PeerGrouP_Site specific theatre. Last accessed on 15 June 2020, via: https://www.peergroup.nl/english/.

Pendall, R., Foster, K. A., \& Cowell, M. (2010). Resilience and regions: Building understanding of the metaphor. Cambridge Journal of Regions, Economy and Society, 3(1), 71-84.

Porter, L., \& Davoudi, S. (2012). The politics of resilience for planning: A cautionary note. Planning Theory and Practice, 13(2), 329-333.

Reeves, M. (2002). Measuring the economic and social impact of the arts: $A$ review. Arts Council of England.

Revell, P., \& Dinnie, E. (2020). Community resilience and narratives of community empowerment in Scotland. Community Development Journal, 55(2), 218-236.

Rogers, M., \& Spokes, J. (2003). Does cultural activity make a difference to community capacity? A key question addressed by the small towns: Big picture project. Community Quarterly, 1(4), 1-8.

Simoniti, V. (2018). Assessing socially engaged art. The Journal of Aesthetics and Art Criticism, $76(1), 71-82$.

Steiner, A., \& Markantoni, M. (2013). Unpacking community resilience through capacity for change. Community Development Journal, 48(3), 1-19. Stocker, L., \& Kennedy, D. (2011). Artistic representations of the sea and coast: Implications for sustainability. Landscapes, 4(2), 97-123.

van der Vaart, G. (2018). Arts \& resilience in a rural community: The value of arts-based community activities in resilience-building in Pingjum, northern Netherlands. Netzodruk.

van der Vaart, G., van Hoven, B., \& Huigen, P. P. P. (2017). 'It is not only an artist village, it is much more than that'. The binding and dividing effects of the arts on a community. Community Development Journal. https://doi. org/10.1093/cdj/bsx055. 
Wang, Q., Coemans, S., Siegesmund, R., \& Hannes, K. (2017). Arts-based methods in socially engaged research practice: A classification framework. Art/research International: A Transdisciplinary Journal, 2(2), 5-39.

White, I., \& O'Hare, P. (2014). From rhetoric to reality: Which resilience, why resilience, and whose resilience in spatial planning? Environment and Planning c: Government and Policy, 32(5), 834-950.

Open Access This chapter is licensed under the terms of the Creative Commons Attribution 4.0 International License (http://creativecommons.org/ licenses/by/4.0/), which permits use, sharing, adaptation, distribution and reproduction in any medium or format, as long as you give appropriate credit to the original author(s) and the source, provide a link to the Creative Commons license and indicate if changes were made.

The images or other third party material in this chapter are included in the chapter's Creative Commons license, unless indicated otherwise in a credit line to the material. If material is not included in the chapter's Creative Commons license and your intended use is not permitted by statutory regulation or exceeds the permitted use, you will need to obtain permission directly from the copyright holder.

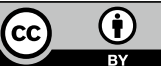

